\title{
The Effect of Premolar Extraction on Overall Bolton Ratio in Class III Malocclusion in RSGMP FKG USU
}

\author{
Andrew Armand \\ Orthodontics Residency Program \\ Faculty of Dentistry, Universitas Sumatera Utara \\ Medan, Indonesia \\ ndrew_nathan@yahoo.com
}

\author{
Nurhayati Harahap \\ Department of Orthodontic \\ Faculty of Dentistry, Universitas Sumatera Utara \\ Medan, Indonesia
}

\author{
Siti Bahirrah \\ Department of Orthodontic \\ Faculty of Dentistry, Universitas Sumatera Utara \\ Medan, Indonesia
}

\begin{abstract}
Tooth extraction is a treatment of choice in the tooth size discrepancy cases in order to achieve appropriate alignment, angulation, and inclination of the teeth. The objective of this study was to determine the effect of premolar extraction on overall Bolton ratio in Class III malocclusion. Samples in this study consisted of 40 study models of subjects with Class III malocclusion that meets the inclusion criteria. Measurements were performed directly on 12 maxillary and mandibular teeth in study model using an electronic digital caliper with accuracy $0.01 \mathrm{~mm}$. Furthermore, the initial overall Bolton ratio was calculated on the whole samples and continued with several hypothetical extractions. After that, the calculation of the overall Bolton ratio in the fifth combination of premolar extraction was done and the results were statistically tested. The results showed that the initial overall Bolton ratio consisted of 5 subjects $(12.5 \%)$ with small overall Bolton ratio, 24 subjects $(60 \%)$ with normal overall Bolton ratio, and 11 subjects (27.5\%) with large overall Bolton ratio. Wilcoxon test showed the effect of premolar tooth extractions on overall Bolton ratio in Class III malocclusion ( $p=0.001$ ). Overall Bolton ratio decreased significantly after the extraction of the premolars in all hypothetical extractions, where normal Bolton ratio was observed in the combination of upper first premolar and lower second premolar extractions. As the conclusion, premolar tooth extraction affects the overall Bolton ratio in Class III malocclusion.
\end{abstract}

Keywords-Overall Bolton ratio, Class III malocclusion, hypothetical extraction

\section{INTRODUCTION}

Tooth size is a very important parameter in diagnosing and determining a treatment plan [1]. This is because without a good balance between the mesiodistal size of the maxillary and mandibular teeth, the final result and stability of an orthodontic treatment becomes difficult to achieve [2].

Orthodontists have used several methods to determine the discrepancy of interarch tooth size in patients undergo orthodontic treatment, among them were Kesling's diagnostic setup, the ratio of canine fossa width to the total width of maxillary tooth width according to Howes, Neff's anterior coefficient method and Bolton analysis [3-9]. The Bolton analysis is the ratio between the mesiodistal number of maxillary and lower teeth that has been used extensively in detecting interarch dental discrepancies [10-12]. The Bolton analysis is divided into two, namely the anterior Bolton ratio and the overall Bolton ratio [13].

In the case of space discrepancy, one of the usual treatment options is tooth extraction, especially premolar teeth to achieve appropriate dental alignment, angulation, and inclination [14]. However, the determination of treatment options is one of the most difficult and critical for orthodontists when preparing a treatment plan [15-17]. Research showed that overall Bolton ratio declines after the extraction of the four first premolar teeth [18]. In addition, Li also reported a decrease in overall Bolton ratio after four extraction combinations namely the extraction of the four first premolars, four second premolars, mandibular first premolars and second premolars, as well as the extraction of maxillary second premolar and mandibular first premolar [19]. Several researchers also reported a significant association between tooth-size ratio and malocclusion type [20-21]. Sperry et al analyzed the Bolton ratios in Class I, II and III malocclusions, and found that subjects with Class III malocclusion had an exaggerated ratio of maxillary tooth size magnitude when compared to subjects with Class I and II [22]. In addition, Nie and Lin also reported that subjects with Class III malocclusion had greater anterior and overall Bolton ratio than subjects with Class I and II [23].

The prevalence of the number and type of malocclusion varies greatly among races and ethnicities, where Class III malocclusion has a high prevalence in Southeast Asian populations [24]. Hardy et al reported 
that the Chinese and Malaysian populations had higher prevalence of Class III Angle malocclusion compared to other racial groups [25]. Ruslin et al also found that mandibular prognathy is the most common abnormality found in Indonesian with an average age of 22.78 [24].

This study aims to determine the overall Bolton Ratio of Class III malocclusion patients after hypothetical extraction in RSGMP FKG USU.

\section{MATERIALS AND METHODS}

The sample in this study were 40 study models of subjects with Class III malocclusion (ANB $=-1.7 \pm$ $0.91^{\circ}$ ) that meets the inclusion criteria. Measurements were performed directly on 12 maxillary and mandibular teeth in study model using an electronic digital caliper (Digimatic Caliper, Mitotoyo) with accuracy $0.01 \mathrm{~mm}$. Measurement starts from the first molar from the first quadrant to the first molar of the second quadrant, then proceed from the first molar from the third quadrant to the first molar teeth of the fourth quadrant. Measurement of the mesiodistal width of the tooth is carried out from the most mesial point of contact to the most distal interproximal contact point of 12 maxillary and mandibular teeth. All of these measurements were done only by one operator.

Subsequently, the initial overall Bolton ratio calculation was calculated on all samples and followed with a combination of hypothetical extraction with the pattern of all first premolars, all second premolars, two mandibular first premolars and two mandibular second premolars, two mandibular second premolars and two mandibular first premolar, and two mandibular first premolars extractions. After that, the overall Bolton ratio calculation was performed on the five hypothetical extractions and the results were tested statistically to see the effect of premolar tooth extraction on the overall Bolton ratio on Class III malocclusion.

\section{RESULTS}

Homogenity tests were performed on all data using Levene test and the results showed that the data came from the same variant. Because of the homogeneous data, then to obtained the overall Bolton ratio in Class III malocclusion was done by using Oneway ANOVA test with the degree of significance $\alpha=0.05$. Table I showed the distribution of overall Bolton ratio data prior to premolars extraction on Class III malocclusion, i.e. five subjects $(12.5 \%)$ with small overall Bolton ratio (88.94 $\pm 0.38)$, 24 subjects with normal ratio $(91.15 \pm 1.07)$, and 11 subjects $(27.5 \%)$ with large Bolton ratio (94.56 \pm 0.91) (Table I).

TABLE I. THE DISTRIBUTION DATA OF OVERALL BOLTON RATIO BEFORE EXTRACTION

\begin{tabular}{|c|c|c|c|}
\hline Overall Bolton ratio & $\mathbf{n}$ & $\boldsymbol{\%}$ & $\mathbf{X} \pm \mathbf{S D}(\boldsymbol{\%})$ \\
\hline Small & 5 & 12.5 & $88.94 \pm 0.38^{\mathrm{a}}$ \\
\hline Normal & 24 & 60 & $91.15 \pm 1.07^{\mathrm{a}}$ \\
\hline Large & 11 & 27.5 & $94.56 \pm 0.91^{\mathrm{a}}$ \\
\hline
\end{tabular}

Table II showed Oneway ANOVA test results (degrees of significance $\alpha=0.05$ ), from the average value of the descriptive data of small overall Bolton ratio after premolars extraction in Class III malocclusion i.e. after extraction of 4P1 $(87.93 \pm 0.34)$, after extraction of 4P2 $(86.02 \pm 0.76)$, after extraction of $2 \mathrm{P} 1$ maxilla and $2 \mathrm{P} 2$ mandible $(87.74 \pm 0.63)$, after extraction of $2 \mathrm{P} 2$ maxilla and $2 \mathrm{P} 1$ mandible $(86.22 \pm 0.76)$, and after extraction of 2P1 mandible (74.09 \pm 0.29$)$.

TABLE II. THE AVERAGE VALUE DISTRIBUTION OF SMALL OVERALL BOLTON RATIO AFTER PREMOLAR EXTRACTION

\begin{tabular}{|c|c|c|c|}
\hline Small overall Bolton ratio & $\mathbf{n}$ & $\mathbf{X} \pm \mathbf{S D}(\boldsymbol{\%})$ & $\mathbf{p}$ \\
\hline Before treatment & 5 & $88.94 \pm 0.38$ & $0.0001^{\mathrm{b}}$ \\
\hline Exo 4P1 & 5 & $87.93 \pm 0.34$ & $0.0001^{\mathrm{b}}$ \\
\hline Exo 4P2 & 5 & $86.02 \pm 0.76$ & $0.0001^{\mathrm{b}}$ \\
\hline Exo 2P1 max \& 2P2 mand & 5 & $87.74 \pm 0.63$ & $0.0001^{\mathrm{b}}$ \\
\hline Exo 2P2 max \& 2P1 mand & 5 & $86.22 \pm 0.76$ & $0.0001^{\mathrm{b}}$ \\
\hline Exo 2P1 mand & 5 & $74.09 \pm 0.29$ & $0.0001^{\mathrm{b}}$ \\
\hline
\end{tabular}

Table III showed Oneway ANOVA test results $(\alpha=$ $0.05)$, where the average value of normal overall Bolton ratio after premolar extraction in Class III malocclusion, after extraction of 4P1 $(90.02 \pm 1.38)$, after extraction of $4 \mathrm{P} 2(89.08 \pm 1.26)$, after extraction of $2 \mathrm{P} 1$ maxilla and $2 \mathrm{P} 2$ mandible $(90.10 \pm 1.40)$, after extraction of $2 \mathrm{P} 2$ maxilla and 2P1 mandible (89.01 \pm 1.26$)$, and after extraction of $2 \mathrm{P} 1$ mandible $(76.11 \pm 1.01)$.

TABLE III. THE AVERAGE VALUE DISTRIBUTION OF NORMAL OVERALL BOLTON RATIO AFTER PREMOLAR EXTRACTION

\begin{tabular}{|l|c|c|c|}
\hline Normal overall Bolton ratio & $\mathbf{n}$ & $\mathbf{X} \pm$ SD (\%) & $\mathbf{p}$ \\
\hline Before treatment & 24 & $91.15 \pm 1.07$ & $0.0001^{\mathrm{c}}$ \\
\hline Exo 4P1 & 24 & $90.02 \pm 1.38$ & $0.0001^{\mathrm{c}}$ \\
\hline Exo 4P2 & 24 & $89.08 \pm 1.26$ & $0.0001^{\mathrm{c}}$ \\
\hline Exo 2P1 max \& 2P2 mand & 24 & $90.10 \pm 1.40$ & $0.0001^{\mathrm{c}}$ \\
\hline Exo 2P2 max \& 2P1 mand & 24 & $89.01 \pm 1.26$ & $0.0001^{\mathrm{c}}$ \\
\hline Exo 2P1 mand & 24 & $76.11 \pm 1.01$ & $0.0001^{\mathrm{c}}$ \\
\hline
\end{tabular}

Table IV showed the Oneway ANOVA test results $(\alpha=0.05)$ of the large overall Bolton ratio after premolar extraction, i.e. after extraction of 4P1 $(93.50 \pm 1.32)$, after extraction of 4P2 $(92.61 \pm 1.53)$, after extraction of 2P1 maxilla and 2P2 mandible $(93.62 \pm 1.34)$, after extraction of 2P2 maxilla and 2P1 mandible (92.48 \pm $1.15)$, and after extraction of $2 \mathrm{P} 1$ mandible (79.15 \pm $0.94)$.

TABLE IV. THE AVERAGE VALUE DISTRIBUTION OF LARGE OVERALL BOLTON RATIO AFTER PREMOLAR EXTRACTION

\begin{tabular}{|l|c|c|c|}
\hline Large overall Bolton ratio & $\mathbf{n}$ & $\mathbf{X} \pm \mathbf{S D}(\%)$ & $\mathbf{p}$ \\
\hline Before treatment & 11 & $94.56 \pm 0.91$ & $0.0001^{\mathrm{d}}$ \\
\hline Exo 4P1 & 11 & $93.50 \pm 1.32$ & $0.0001^{\mathrm{d}}$ \\
\hline Exo 4P2 & 11 & $92.61 \pm 1.53$ & $0.0001^{\mathrm{d}}$ \\
\hline Exo 2P1 max \& 2P2 mand & 11 & $93.62 \pm 1.34$ & $0.0001^{\mathrm{d}}$ \\
\hline Exo 2P2 max \& 2P1 mand & 11 & $92.48 \pm 1.15$ & $0.0001^{\mathrm{d}}$ \\
\hline Exo 2P1 mand & 11 & $79.15 \pm 0.94$ & $0.0001^{\mathrm{d}}$ \\
\hline
\end{tabular}

Figure 1 showed the number of subjects with the highest normal overall Bolton ratio was found in the 
maxillary first premolar and mandibular second premolar extraction pattern, while the most significant change in overall Bolton ratio $(p<0.05)$ occurred in the mandibular first premolar extraction group, where all overall Bolton Ratio become smaller after the premolar extraction.

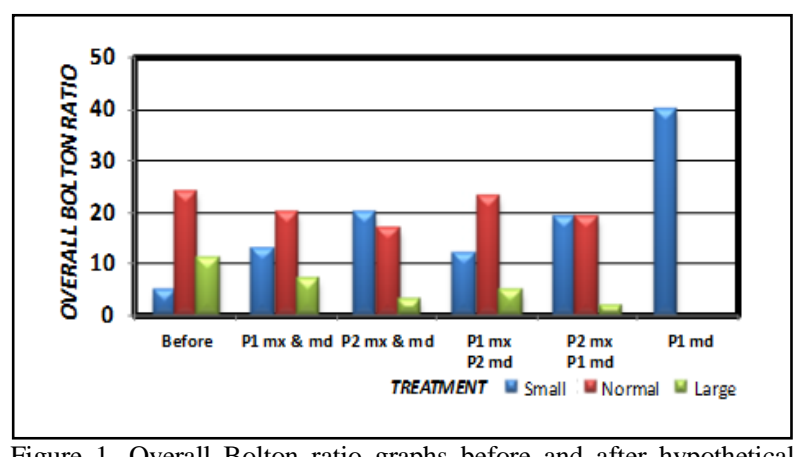

Figure 1. Overall Bolton ratio graphs before and after hypothetical extraction.

\section{DISCUSSION}

The sample in this study is a study model of patients that meet the inclusion criteria with good conditions, no fractures and no porous, with total 40 subjects. The subjects of the study should have Class III Angle malocclusion that was seen from the relationship between the maxillary and mandibular first molar and have ANB value smaller than $0^{\circ}$.

The selected subjects were subjects with age range from 17 to 35 years, this is because the initial permanent tooth was the period chosen to produce more accurate dental measurements because, at this stage, there was minimal damage and attrition in most individuals [26]. In addition, the subject of this study was not differentiated by gender, because the previous study showed that there was no significant difference in the overall Bolton ratio between male and female subjects [27].

The overall Bolton ratio calculation begins by calculating the mesiodistal width of the permanent first molar to permanent first molar on the other side of maxillary and mandibular, which is performed on the study model using an electronic digital caliper (Digimatic Caliper, Mitotoyo) with accuracy $0.01 \mathrm{~mm}$. All measurements were done only by one operator. In one day, measurements can only be done on 5 study models to avoid eyestrain, so the measurements result will remain accurate. The measurement is done back after 2 weeks interval to see the measurement accuracy.

Based on the Wilcoxon test, the results of this study showed the effect of the extraction of all first premolars on the overall Bolton ratio, where the overall Bolton ratio decreased significantly in all groups. This result is similar to the study done by Heusdens et al stated that there was a significant difference in overall Bolton ratio after the maxillary and mandibular first premolars extraction [28].

The results of this study showed that the extraction of all second premolars had an effect on the overall Bolton ratio, where the overall Bolton ratio decreased significantly in all categories of Bolton ratios. The results were consistent with the study by Saatci and Yukai, which found a decreased in the Bolton ratio after the extraction of all the second premolar teeth and maxillary second premolar teeth and the mandibular first premolar [19].

The extraction of two maxillary first premolars and two mandibular second premolars showed an effect on the overall Bolton ratio, in which overall Bolton ratio had decreased significantly in all categories of Bolton ratios. This is not in accordance with research conducted by Saatci and Yukai, where they suggest that there was an increased in overall Bolton ratio after the extraction of all first premolar, as well as the maxillary first premolars and mandibular second premolars [19]. This may be due to the differences of mesiodistal width size in the research samples used between this study and previous studies.

The results of this study showed that the extraction of mandibular second premolars and mandibular first premolars resulted in a significant decreased in all categories of Bolton ratios. This results were consistent with the research by Tong et al, which stated that there was a significant decrease after the removal of fourth second premolar teeth, as well as the maxillary second premolar and the mandibular first premolar, this is because the maxillary second premolar have smaller size when compared with maxillary first premolar, so the overall Bolton ratio will be smaller after the maxillary second premolars extraction than the maxillary first premolars extraction [27].

Overall, the results of this study showed that the effect of premolar tooth extraction on all combinations of extraction leads to a decreased in overall Bolton ratio, which was consistent with the results of a study conducted by Tong et al that also found changes in the Bolton ratio in all combinations of tooth extraction [27]. The overall decreased in Bolton ratio across all combinations of extraction is due to the mesiodistal ratios of first or second mandibular teeth smaller when compared to the mesiodistal width of the first or second premolar tooth in the mandible.

The effect of several different extraction patterns on the Bolton ratios is very useful, not only in determining the overjet, overbite and final occlusion of the patient, but also in planning the extraction pattern and the need for interproximal reduction [21].

\section{REFERENCES}

[1] P.V. Kale, D.R. Chhajed, S.S. Khapli, N.R. Tripathi, G.G. Randhawa, "Extraction: A parameter in Bolton ratio," J. Dent. Allied Sc., vol. 4, pp. 3-7, 2015.

[2] M.L.A. Hyder, M.S.A Mamun, M.Z. Hossain, "Tooth size discrepancies among different malocclusions in a Bangladeshi orthodontic population," Bangladesh J. Orthod. and Dentofacial Orthop., vol. 2, pp. 8-17, February 2012.

[3] S.S. Smith, P.H. Buschang, E. Watanabe E, "Interarch tooth size relationship of 3 populations: "Does Bolton's analysis apply?" Am. J. Orthod. Dentofacial Orthop., vol. 117, pp. 169-174, 2000 .

[4] H.D. Kesling, "The philosophy of the tooth positioning appliance,” Am. J. Orthod., vol 31, pp. 297-340. 1945. 
[5] A.E. Howes, "Case analysis and treatment planning based upon the relationship of the tooth material to its supporting bone," Am. J. Orthod., vol. 33, pp. 499-533, 1947.

[6] C.W. Neff, "Tailored occlusion with anterior coefficient," Am. J. Orthod., vol. 35, pp. 309-13, 1949.

[7] C.W. Neff, "The size relationship between the maxillary and mandibular anterior segments of the dental arch," Angle Orthod., vol. 27, pp.138-47, 1957.

[8] W.A. Bolton, "Disharmonies in tooth size and its relation to the analysis and treatment of malocclusions," Angle Orthod., vol. 28, pp. 113-30, 1958.

[9] W.A Bolton, "The clinical application of a tooth size analysis," Am. J. Orthod., vol. 48, pp. 504-29, 1962.

[10] V.V. Subbarao, R.R. Regalla, V. Santi, G. Anita, V.S. Kattimani, "Interarch tooth size relationship of Indian populations: Does Bolton's analysis apply?” J. Contemp. Dent. Pract., vol. 15, pp. 103-107, January 2014.

[11] T. Al-Gunaid, M. Yamaki, I. Saito, "Mesiodistal tooth width and tooth size discrepancies of Yemeni Arabians: A pilot study,” J. Orthodont. Sci., vol. 1, pp. 40-5, 2012.

[12] A.H.A Hashim, A.H.M. Eldin, H.A. Hashim, "Bolton tooth size ratio among Sudanese Population sample: A preliminary study," J. Orthodont. Sci., vol. 4, pp. 77-82, 2012.

[13] S.I. Bhalaji, Orthodontics - the art and science. $3^{\text {rd }}$ ed., New Delhi: Arya (Medi) Publishing House, 2013, pp. 178-179.

[14] P. Kumar, V. Singh, P. Kumar, P. Sharma, R. Sharma, "Effects of premolar extractions on Bolton overall ratios and tooth-size discrepancies in a north Indian population," J. Orthodont. Sci., vol. 2, pp. 23-7, 2013.

[15] E.L. Gottlieb, A.H. Nelson, D.S. Vogels, "JCO study of orthodontic diagnosis and treatment procedures. Part 1 overall results," J. Clin. Orthod., vol. 20, pp. 612-625, 1986.

[16] E.L. Gottlieb, A.H. Nelson, D.S Vogels, "JCO study of orthodontic diagnosis and treatment procedures. Part 1 results and trends," J. Clin. Orthod., vol. 30, pp. 615-629, 1996.

[17] W.R. Proffit, "Forty-year review of extraction frequencies at a university orthodontic clinic," Angle Orthod., vol. 64, pp. 407414, 1994.
[18] Y.C. Li, Z.X. Zhu, M. Li, et al., "The effect of premolar extractions on Bolton index," Chin. J. Orthod., vol. 8, pp. 5961, 2001.

[19] P. Saatci, F. Yukay, "The effect of premolar extractions on tooth size discrepancy,” Am. J. Orthod. Dentofacial Orthop., vol. 111, pp. 428-434, 1997.

[20] T.A. Ta, J.K.Y. Ling, U. Hagg, "Tooth-size discrepancies among different occlusion groups of southern Chinese children," Am. J. Orthod. Dentofacial Orthop., vol. 120, pp. 556-8, 2001.

[21] E. Araujo, M. Souki, "Bolton anterior tooth size discrepancies among different malocclusion groups," Angle Orthod., vol. 73, pp. 307-13, 2003.

[22] F.F.H. Al Sulaimani, A.R. Afify, "Bolton analysis in different classes of malocclusion in a Saudi Arabian sample," Egyptian Dent. J., vol. 52, pp. 1119-1125, February 2006.

[23] Q. Nie, J. Lin, "Comparison of intermaxillary tooth size discrepanciesamong different malocclusion groups," Am. J. Orthod. Dentofacial Orthop., vol. 116, pp. 539-544, 1999.

[24] M. Ruslin, et al, "The anthropological aspects of dentofacial deformities: A comparison between Indonesian and Dutch cohorts," Dentofasial, vol. 13, pp. 48-54, January 2014.

[25] D.K. Hardy, Y.P. Cubas, M.F. Orellana, "Prevalence of angle class III malocclusion: A systematic review and meta-analysis,' Open J. of Epidemiology, vol. 2, pp. 75-82, 2012.

[26] H.A. Hashim, S. Al-Ghamdi, "Tooth width and arch dimensions in normal and malocclusion samples: An odontometric study," J. Contemp. Dent. Pract., vol. 2, pp. 36-51, 2005.

[27] H. Tong, D. Chen, L. Xu, P. Liu, "The effect of premolar extractions on tooth size discrepancies," Angle Orthod., vol. 74, pp. 508-11, 2004.

[28] M. Heusdens, L. Dermaut, R. Verbeeck, "The effect of tooth size discrepancy on occlusion: an experimental study," Am. J. Orthod. Dentofacial Orthop., vol. 117, pp. 184-91, 2000.

[29] T. Endo, K. Ishida, I. Shundo, K. Sakaeda, S. Shimooka, "Effects of premolar extractions on Bolton overall ratios and tooth-size discrepancies in a Japanese orthodontic population," Am. J. Orthod. Dentofacial Orthop., vol. 137, pp. 508-14, April 2010 